\begin{tabular}{|c|c|c|c|c|c|}
\hline JRL & Vol. 12 & No. 2 & Hal : 107-117 & $\begin{array}{c}\text { Jakarta, } \\
\text { Desember 2019 }\end{array}$ & $\begin{array}{c}\text { p-ISSN : 2085.38616 } \\
\text { e-ISSN : 2580-0442 }\end{array}$ \\
\hline
\end{tabular}

\title{
OPTIMALISASI KINERJA PERANGKAT PENINGKAT PH BERBASIS RESIN MAGNESIUM OKSIDA UNTUK PRODUKSI AIR SIAP MINUM
}

\author{
Muhammad Haqqiyuddin Robbani dan Imam Setiadi \\ Pusat Teknologi Lingkungan - BPPT \\ Gd. Geostech No. 820, Kawasan PUSPIPTEK, Serpong \\ Email : muhammad.haqqiyuddin@bppt.go.id ; imam.setiadi@bppt.go.id
}

\begin{abstract}
Abstrak
Rendahnya nilai $\mathrm{pH}$ air yang dihasilkan oleh teknologi pengolahan air siap minum (Arsinum) berbasis membran reverse osmosis (RO) masih menjadi salah satu permasalahan yang kerap terjadi. Remineralisasi atau penambahan kembali ion mineral merupakan salah-satu alternatif teknologi yang dapat digunakan untuk menyelesaikan permasalahan tersebut. Tujuan dari penelitian ini adalah untuk mengetahui kondisi operasi (waktu tinggal) terbaik dalam proses peningkatan $\mathrm{pH}$ air siap minum menggunakan resin magnesium oksida dengan tetap memperhatikan nilai TDS yang masih aman untuk dikonsumsi. Penelitian dilakukan dengan memvariasikan laju alir serta jumlah cartridge yang nantinya akan berkaitan dengan lamanya waktu tinggal atau waktu kontak antara air umpan dengan resin magnesium oksida. Penambahan resin magnesium oksida nyatanya mampu meningkatkan nilai $\mathrm{pH}$ larutan umpan hingga mencapai nilai $\mathrm{pH} 9$ (sembilan). Adapun kadar TDS air produk yang terukur untuk semua waktu tinggal yang diatur dalam variabel penelitian ini masih dalam batas aman untuk dikonsumsi. Hasil penelitian ini diharapkan dapat menjadi bahan pertimbangan teknis untuk kemudian dapat diaplikasikan dalam proses produksi air siap minum.
\end{abstract}

kata kunci: $\mathrm{pH}$, air siap minum, reverse osmosis, remineralisasi, magnesium oksida 


\title{
PERFORMANCE OPTIMIZATION OF MAGNESIUM OXIDE RESIN BASED pH INCREASER DEVICE FOR DRINKING WATER PRODUCTION
}

\begin{abstract}
The low $\mathrm{pH}$ value of the potable water produced by the reverse osmosis (RO) membrane-based water treatment technology is still one of the problems that often occurs. Remineralization or re-adding of mineral ions is an alternative technology that can be used to resolve these considerations. The purpose of this research is to study the best operating conditions (residence time) in the process of increasing the $\mathrm{pH}$ of ready-to-drink water using magnesium oxide resin while still taking into account the TDS value that is still safe for consumption. The research was carried out by varying the flow rate and the number of cartridges which relate to the duration of residence or contact time between feed water and magnesium oxide resin. The addition of magnesium oxide resin in fact can increase the $\mathrm{pH}$ value to reach a $\mathrm{pH}$ value of 9 (nine). While the measured product water TDS levels for all the residence times specified in this research variable are still within the safe limits for consumption. The results of this study are expected to become technical considerations and then can be applied in the process of producing drinking water.
\end{abstract}

keywords : $\mathrm{pH}$, potable water, reverse osmosis, remineralization, magnesium oxide 


\section{PENDAHULUAN}

\subsection{Latar Belakang}

Badan Pusat Statistik (BPS) melalui hasil Survei Sosial Ekonomi Nasional (Susenas) melaporkan masih adanya ketimpangan sebaran akses masyarakat umum untuk mendapatkan sumber air minum layak di 34 provinsi indonesia (BPS, 2017). Walapun secara nasional terjadi peningkatan akses hingga mencapai angka 72,04 persen, namun demikian tidak ada satupun provinsi yang memiliki akses hingga 100 persen. Di sisi lain terdapat pula beberapa provinsi yang masih berada di bawah 50 persen proporsi rumah tangga yang memiliki akses terhadap air minum layak. Dari data tersebut dapat diketahui bahwa penyediaan akses terhadap air minum yang layak masih menjadi permasalahan di Indonesia khususnya di daerah terpencil.

Berdasarkan hasil Susenas, penyediaan akses terhadap air minum yang layak atau biasa disebut air siap minum umumnya berasal dari sumur terlindung, air tanah (yang dipompa), dan air minum dalam kemasan. Sejak tahun 2012 hingga tahun 2017, terjadi lonjakan persentase jumlah rumah tangga yang menggunakan air minum dalam kemasan untuk memenuhi kebutuhan air siap minum hingga 38,85 persen. Hal ini merupakan dampak dari semakin tercemarnya sumber air dari sumur terlindung dan air tanah yang dipompa. Selain itu, perkembangan teknologi pengolahan air siap minum berbasis membran Reverse Osmosis (RO) yang sangat pesat juga dapat menjadi alasan yang mendasari fenomena tersebut.
Tingginya

kecepatan

produksi serta semakin murahnya teknologi pengolahan air siap minum berbasis RO memicu pertumbuhan bisnis air minum dalam kemasan (Said, 2009). RO juga merupakan teknlogi pengolahan air siap minum yang paling banyak diaplikaskan dalam skala rumah tangga. Penggunaan membran yang semakin tipis dan kebutuhan ruang yang semakin minim menjadikan teknologi $\mathrm{RO}$ semakin umum digunakan (Ariyanti \& Widiasa, 2011). Badan Pengkajian dan Penerapan Teknologi (BPPT) turut melakukan inovasi serta difusi teknologi pengolahan air siap minum (Arsinum) berbasis $\mathrm{RO}$ selama kurang lebih satu dekade terakhir sebagai upaya pemenuhan kebutuhan akan air minum masyarakat di pelbagai pelosok negeri (Said, 2009; Herlambang, 2010; Setiadi \& Kristyawan, 2018; Setiadi, 2019; Yudo \& Sitomurni, 2019).

Dalam perjalanannya, penerapan teknologi Arsinum ini masih menimbulkan permasalahan diantaranya yakni rendahnya nilai $\mathrm{pH}$ air yang dihasilkan. Nilai $\mathrm{pH}$ yang dihasilkan masih belum mencapai standar yang aman untuk dikonsumsi berdasarkan Permenkes nomor 492/2010. Rendahnya nilai $\mathrm{pH}$ ini disebabkan oleh bereaksinya sebagian ion air pada produk $\mathrm{RO}$ dengan gas $\mathrm{CO}_{2}$ sehingga menyebabkan hadirnya ion hidrogen bebas (Qin dkk., 2005). Qin dkk (2005) juga mengemukakan bahwa nilai $\mathrm{pH}$ permeate atau air produk $\mathrm{RO}$ akan mengalami penurunan apabila air umpan yang masuk memiliki nilai $\mathrm{pH}$ lebih tinggi dari 4,5 akibat dari ikut tersaringnya ion basa lemah 
$\mathrm{HCO}_{3}^{-}$yang dominan terkandung pada umpan pada proses penyaringan. Sehingga diperlukan suatu alternatif teknologi untuk dapat menaikkan kembali nilai $\mathrm{pH}$ air produksi $\mathrm{RO}$ tersebut.

Remineralisasi

atau

penambahan kembali ion mineral merupakan salah-satu alternatif teknologi yang dapat digunakan untuk meningkatkan nilai $\mathrm{pH}$ air produk olahan RO (Ruggieri dkk., 2008). Remineralisasi yang umum digunakan adalah metode kontak langsung dengan resin alkali. Metode ini memiliki keunggulan dari sisi kecepatan produksi bila dibandingkan dengan metode elektrolisis. Resin alkali yang umumnya digunakan adalah resin berbasis kalsium dan magnesium karena dua senyawa alkali tersebut sudah dikategoriakan aman untuk dikonsumsi dalam dosis tertentu menurut WHO (Cotruvo, 2006). Produk-produk peningkat $\mathrm{pH}$ berbasis resin alkali yang banyak dijual di pasaran umumnya menggunakan resin berbasis kalsium seperti kalsium karbonat. Sedangkan resin alkali berbasis magnesium masih sangat jarang digunakan.

Oleh karenannya, tulisan ini akan difokuskan pada perangkat peningkat $\mathrm{pH}$ berbasis resin senyawa magnesium oksida. Dengan harapan, perangkat peningkat $\mathrm{pH}$ berbasis resin magnesium oksida ini dapat menjadi alternatif solusi dengan tetap memperhatikan beberapa parameter yang masih aman untuk dikonsumsi berdasarkan Permenkes 492/2010. Namun demikian, apabila proses remineralisasi dilakukan secara berlebihan, tentunya akan meningkatkan kandungan TDS dalam air minum yang dihasilkan. Sehingga, diperlukan suatu ujicoba untuk dapat menentukan kondisi operasi terbaik agar air minum yang dihasilkan mencapai $\mathrm{pH}$ yang diinginkan dengan kandungan TDS yang masih dalam batas aman untuk dikonsumsi.

\subsection{Tujuan Penelitian}

Tujuan dari penelitian ini adalah untuk mengetahui kondisi operasi (waktu tinggal) terbaik dalam proses peningkatan $\mathrm{pH}$ air siap minum menggunakan resin magnesium oksida dengan tetap memperhatikan nilai TDS yang masih aman untuk dikonsumsi. Hasil penelitian ini diharapkan dapat menjadi bahan pertimbangan teknis untuk kemudian dapat diaplikasikan dalam proses produksi air siap minum.

\section{METODE PENELITIAN}

\section{1. Bahan}

Resin magnesium oksida yang digunakan adalah jenis Corosex yang diproduksi oleh Clack Corporation (USA) dengan kemurnian 97\% dan berukuran sekitar 6-16 mesh dengan uniform coefficient 1,7. Air umpan yang digunakan berasal dari unit pengolahan air siap minum (Arsinum) produksi Pusat Teknologi Lingkungan BPPT.

\subsection{Metode}

Untuk memudahkan uraian terkait metode penelitian, disertakan pula diagram alir proses berserta gambaran peralatan yang digunakan (Gambar 1). Air umpan hasil olahan unit Arsinum (1) dialirkan menggunakan pompa jenis sentrifugal semi-jetpump (2) 
berkapasitas 7 liter per menit menuju housing cartridge filter (5) yang telah diisi dengan resin magnesium oksida. Cartridge filter yang digunakan berukuran $10 \times 2,5$ inci dengan volume sebesar 0,8 liter. Laju alir menuju housing cartridge filter diatur menggunakan globe valve (3) dan diukur menggunakan flowmeter (4). air produk olahan hasil kontak dengan resin magnesium oksida kemudian dialirkan menuju tangki penampungan produk untuk diukur nilai $\mathrm{pH}$ dan TDS-nya(6). $\mathrm{pH}$ meter yang digunakan adalah Horiba LAQUAtwin $\mathrm{pH}-11$ dan Merck MQuant $\mathrm{pH}$-indicator strips (nonbleeding) $\mathrm{pH} \quad 0$ - 14 Universal indicator. Sementara TDS meter yang digunakan adalah Hanna HI98301. Penelitian dilakukan dengan memvariasikan laju alir (2-7 liter per menit) serta jumlah cartridge (1 dan 2 buah) yang nantinya akan berkaitan dengan lamanya waktu tinggal atau waktu kontak antara air umpan dengan resin magnesium oksida. Untuk meningkatkan validitas data yang didapat, penelitian dilakukan sebanyak 3 (tiga) kali percobaan/running, kemudian hasilnya dirata-rata.

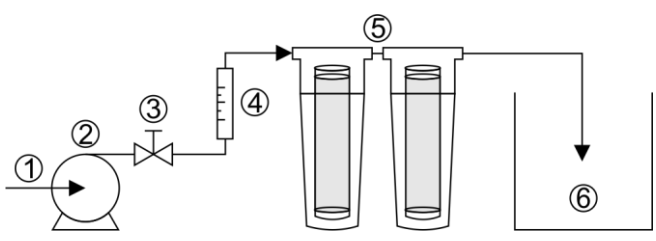

Gambar 1. Diagram alir proses peningkatan $\mathrm{pH}$

Adapun persamaan yang menjelaskan hubungan antara laju alir terhadap waktu tinggal adalah:

$$
t=V / Q
$$

(1)

\section{Keterangan}

\begin{tabular}{ll}
\multicolumn{1}{c}{ : Waktu tinggal (menit) } \\
$\mathrm{V}$ & : Volume cartridge \\
menit) & : Laju alir (liter per
\end{tabular}

\section{HASIL DAN PEMBAHASAN}

\subsection{Pengaruh waktu tinggal terhadap pH air siap minum \\ Observasi hubungan antara} waktu tinggal air umpan pada cartridge berisikan resin magnesium oksida terhadap peningkatan nilai $\mathrm{pH}$ dilakukan untuk mengetahui kondisi operasi yang optimal saat diaplikasikan nantinya. Suatu kondisi operasi dapat dikatakan optimal apabila masuk dalam kriteria efektif dan efisien. Efektif disini berkaitan erat dengan ketercapaian target $\mathrm{pH}$ yang diharapakan yakni sesuai dengan Permenkes 492/2010 bahwa prasyarat $\mathrm{pH}$ air minum berkisar antara 6,5 - 8,5. Sedangkan efisien berhubungan dengan sumberdaya bahan baku yang digunakan yaitu resin magnesium oksdia. Dengan kata lain kondisi operasi optimal dapat dicapai apabila target $\mathrm{pH}$ yang diinginkan telah terpenuhi dengan penggunaan resin magnesium oksida seminimal mungkin.

Variabel yang sangat berpengaruh terhadap kondisi operasi (waktu tinggal) adalah laju alir umpan dan volume dari cartridge filter yang digunakan. Laju alir umpan yang merupakan hasil keluaran membran $\mathrm{RO}$ memiliki 
kaitan langsung dengan waktu tinggal. Semakin besar laju alir umpan maka semakin singkat waktu kontak antara air umpan dengan resin magnesium oksida. Begitu pula sebaliknya, waktu kontak air umpan akan semakin lama bila laju alir umpan semakin kecil. Laju alir umpan memiliki besaran yang berbeda-beda tergantung kapasitas dari membran itu sendiri. Umumnya untuk pengolahan air siap minum membran $\mathrm{RO}$ yang digunakan adalah jenis Tape Water atau Brackish Water dengan kapasitas maksimal 7 liter per menit. Dalam penelitian ini digunakan variasi laju alir yang berkisar antara 2-7 liter per menit agar nantinya dapat langsung diaplikasikan pada unit pengolah air siap minum. Laju alir umpan yang terlalu lambat tentunya akan berpengaruh terhadap kapasitas produksi air siap minum. Sehingga, perlunya dilakukan investigasi lebih lanjut terkait laju alir yang efisien guna meningkatkan $\mathrm{pH}$ air siap minum tanpa menurunkan kapasitas produksinya.

Adapun besaran volume cartridge filter, yang berfungsi sebagai wadah untuk menampung resin magnesium oksida, berkontribusi besar terhadap durasi waktu tinggal atau waktu kontak air umpan dengan resin. Semakin besar volume cartridge filter, semakin lama pula waktu kontak antara air umpan dengan resin magnesium oksida. Begitu pula sebaliknya, semakin kecil volume wadah penampung resin, semakin singkat pula waktu kontaknya. Volume cartridge filter umumnya memiliki keterbatasan yakni ukuran yang ada di pasaran hanya berkisar 0,8-1,6 liter saja. Dengan kata lain, untuk memperbesar volume cartridge filter harus dilakukan penyusunan beberapa unit secara seri maupun paralel. Dalam penelitian ini dilakukan uji coba penyusunan 2 unit cartridge filter berisikan magnesium oksida secara seri sebagai referensi aplikasi ke depannya sekaligus meningkatkan volume kontak. Disisi lain, volume cartridge filter yang terlalu besar akan menurunkan produktifitas dari unit pengolah air siap minum itu sendiri karena waktu tinggal yang terlalu lama. Oleh karenanya besaran volume cartridge yang sesuai kebutuhan perlu diidentifikasi lebih lanjut agar tetap dapat mencapai target $\mathrm{pH}$ tanpa menurunkan produktifitas.

Pada Gambar 2 disajikan grafik perbandingan profil $\mathrm{pH}$ air minum yang telah dilewatkan pada cartridge filter yang berisi resin magnesium oksida dengan variasi waktu tinggal. Hasil pengukuran yang ditunjukkan oleh $\mathrm{pH}$ meter jenis lakmus memperlihatkan kenaikan nilai $\mathrm{pH}$ yang cukup siginifikan disetiap peningkatan waktu tinggal. Hal ini berlaku pada kondisi resin magnesium oksida terisi penuh baik di 1 cartridge maupun 2 cartridge. Nilai $\mathrm{pH}$ air umpan yang diharapkan $(6,5-8,5)$ baru tercapai pada saat waktu tinggal berdurasi lebih dari atau sama dengan 16 detik. Pada 4 durasi waktu tinggal awal yaitu 6, 8, 10, dan 12 detik, nilai $\mathrm{pH}$ yang didapatkan masih berkisar pad angka 6 - 6,3. Pada saat waktu tinggal air umpan diatur selama 16 detik, didapatkan nilai $\mathrm{pH}$ sebesar 7,0 . Nilai $\mathrm{pH}$ yang sama ditunjukkan pula saat waktu tinggal air umpan dinaikkan menjadi 19 detik. Kenaikan nilai $\mathrm{pH}$ kembali terjadi pada saat waktu tinggal dinaikkan menjadi 24, 32, dan 48 detik yakni 
masing-masing bernilai $8,8,33$, dan 9.

Adapun hasil pembacaan nilai $\mathrm{pH}$ menggunakan alat $\mathrm{pH}$ meter portabel menunjukan kisaran angka 8 pada semua waktu tinggal dengan kenaikan maksimal 0,7. Data tersebut tetap menunjukkan kenaikan $\mathrm{pH}$ pada air umpan namun tidak sesignifikan hasil pembacaan $\mathrm{pH}$ meter jenis lakmus. Fenomena ini kemungkinan besar disebabkan oleh lebih sensitifnya probe pada alat $\mathrm{pH}$ meter portabel dibandingkan dengan $\mathrm{pH}$ meter jenis lakmus. Bila merujuk hasil pembacaan dari pH meter portabel, nilai $\mathrm{pH}$ yang diharapkan sudah mampu tercapai dengan waktu tinggal paling rendah sekalipun (6,86 detik).

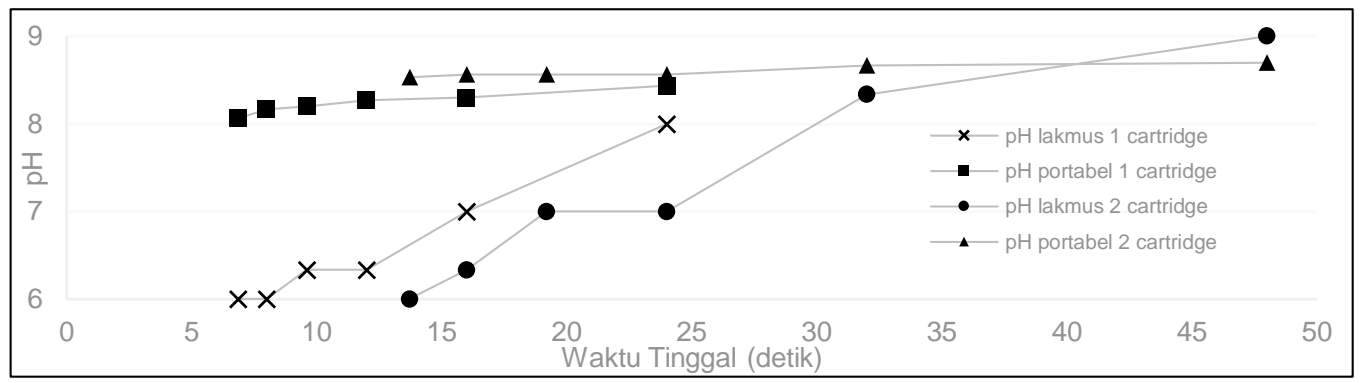

Gambar 2. Perbandingan profil pH air minum menggunakan alat uji yang berbeda

Pada prinsipnya, peningkatan nilai $\mathrm{pH}$ pada air minum yang dilewatkan pada cartridge filter berisikan resin magnesium oksida ini disebabkan oleh pelarutan resin ke dalam aliran air minum dengan jumlah dan laju pelarutan tertentu. Pelarutan ini kemudian diikuti dengan adanya kecenderungan senyawa magnesium oksida (MgO) untuk bereaksi dengan air $\left(\mathrm{H}_{2} \mathrm{O}\right)$ dan menghasilkan produk senyawa magnesium hidroksida $\left(\mathrm{Mg}(\mathrm{OH})_{2}\right)$ yang mengikuti persamaan reaksi:

$$
\mathrm{MgO}+\mathrm{H}_{2} \mathrm{O}<-->\mathrm{Mg}(\mathrm{OH})_{2}
$$

$\begin{array}{lrc}\text { Adapun } & \text { senyawa } & \text { magnesim } \\ \text { hidroksida } & \text { dapat } & \text { terionisasi } \\ \text { sempurna dalam } & \text { air dan } \\ \text { menghasilkan ion } & \text { Magnesium }\end{array}$

$\left(\mathrm{Mg}^{2+}\right)$ dan ion $\mathrm{OH}^{-}$berdasarkan persamaan reaksi:

$\mathrm{Mg}(\mathrm{OH})_{2}<-->\mathrm{Mg}^{2+}+2 \mathrm{OH}^{-}$ (3)

Sebagai hasilnya, tingkat kebasaan (konsentrasi $\mathrm{OH}^{-}$) dan kesadahan (konsentrasi $\mathrm{Mg}^{2+}$ ) akan mengalami peningkatan seiring dengan pertambahan jumlah senyawa magnesium oksida yang ada di dalam aliran air minum. Fenomena demikian sering disebut dengan remineralisasi akibat dari bertambahnya jumlah ion mineral, dalam hal ini ion magnesium, sebagai hasil samping dari penambahan resin mineral tertentu dengan maksud meningkatkan nilai $\mathrm{pH}$ saja pada awalnya. Namum demikian penambahan resin mineral nyatanya mampu mengembalikan 
sebagian kandungan mineral dalam air sehingga memiliki nilai gizi yang masih sesuai dengan standar nutrisi air minum (WHO, 2006).

Fenomena tersebut sejalan dengan penelitian Ruggieri, dkk (2008) yang melaporkan bahwa senyawa-senyawa mineral seperti kalsium $\left(\mathrm{CaCO}_{3}\right)$ dan magnesium $\left(\mathrm{MgCO}_{3}\right)$ serta turunannya memiliki kecenderungan untuk bereaksi dengan molekul air $\left(\mathrm{H}_{2} \mathrm{O}\right)$. Senyawa-senyawa mineral tersebut kemudian akan terionisasi sempurna di dalam air dan menghasilkan ion mineral $\left(\mathrm{Ca}^{2+}\right.$ dan $\mathrm{Mg}^{2+}$ ) serta meningkatkan alkalinitas Iarutan tersebut. Pada penelitian tersebut digunakan kapur sebagai resin remineralisasi yang mengandung senyawa kalsium tinggi namun rendah senyawa magnesium. Oleh karenanya tulisan ini hanya difokuskan pada penggunaan resin magnesium oksida saja untuk mengetahui bagaimana fenomena yang terjadi.

Penambahan resin magnesium oksida nyatanya mampu meningkatkan nilai $\mathrm{pH}$ larutan umpan secara signifikan. Dengan memvariasikan lama waktu tinggal dapat diketahui bahwa perangkat peningkat $\mathrm{pH}$ berbasis resin magnesium oksida ini cukup optimal untuk mencapai prasyaratan air minum pada waktu tinggal minimal 16 detik. Adapun variasi jumlah cartridge akan berpengaruh bila ingin dilakukan peningkatan laju alir umpan untuk mencapai waktu tinggal yang optimal. Bila mempertimbangkan spesifikasi peralatan yang ada dipasaran agaknya peningkat $\mathrm{pH}$ berbasis resin magnesium oksida ini sangat mampu untuk dijadikan alternatif solusi permasalahan rendahnya $\mathrm{pH}$ air produk.

\subsection{Pengaruh waktu tinggal terhadap kenaikan TDS air siap minum}

Penelusuran pengaruh waktu tingal terhadap kenaikan TDS air siap minum dilakukan untuk mengkonfirmasi besaran waktu tinggal yang sudah dinyatakan optimal pada subbab sebelumnya. Kadar TDS air siap minum yang $\mathrm{pH}$ sudah ditingkatkan melalui proses remineralisasi menggunakan resin magnesium oksida tentunya harus tetap sesuai dengan Permenkes 492/2010 yakni maksimal 500 mg per liter. Adapun kelarutan magnesium oksida dalam air pada suhu 30 derajat celcius adalah 86 mg per liter (Patnaik, 2003). Sehingga seharusnya penambahan resin magnesium oksida ini tidak akan membuat air minum yang diproduksi menjadi tidak layak minum.

Variabel yang digunakan masih sama dengan pembahasan pada subbab sebelumnya. Hanya saja, parameter yang diukur difokuskan pada kadar TDS yang terkandung oleh air produk pasca dikontakkan dengan resin magnesium oksida. Pada penelitian ini kandungan TDS pada air umpan diasumsikan mendekati nilai nol untuk memudahkan perhitungan. Adapun kandungan spesifik logam yang terlarut tidak dibahas dalam penelitian ini. 


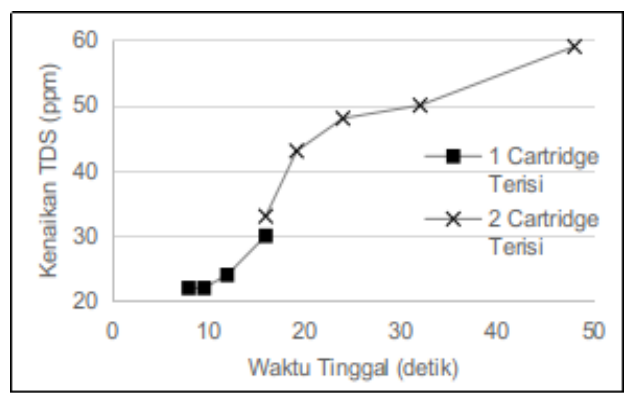

Gambar 3. Profil kenaikan TDS air minum terhadap waktu tinggal

Pada Gambar 3 diperlihatkan hasil pembuatan grafik profil kadar TDS air produk yang telah dikontakkan dengan resin magnesium oksida dengan perbandingannya pada setiap waktu tinggal. Hasil pengukuran menunjukkan adanya kenaikan kadar TDS yang cukup signifikan untuk setiap penambahan lamanya waktu tinggal air umpan dalam wadah kontaktor. Kadar tertinggi yang dicapai adalah sebesar $59 \mathrm{mg}$ TDS per liter yakni pada waktu tinggal terlama (48 detik). Sedangkan kadar terendah yang didapatkan adalah sebesar $22 \mathrm{mg}$ TDS per liter yaitu pada waktu tinggal 8 dan 9,6 detik. Adapun kadar TDS air produk yang terukur untuk semua waktu tinggal yang diatur dalam variabel penelitian ini masih dalam batas aman sesuai dengan Permenkes 492/2010 (<500 mg per liter).

Peningkatan kadar TDS ini ditenggarai oleh pelarutan $\mathrm{MgO}$ ke dalam air yang kemudian berekasi membentuk $\mathrm{Mg}(\mathrm{OH})_{2}$ dan terionisasi sempuna menjadi ion $\mathrm{Mg}^{2+}$ seperti yang telah dijabarkan pada subbab sebelumnya. Penambahan ion $\mathrm{Mg}^{2+}$ ini kemudian dibaca oleh TDS meter sebagai penambahan jumlah padatan terlarut yang berkaitan dengan konduktifitas. Dengan penambahan ion $\mathrm{Mg}^{2+}$ yang berasal dari resin magnesium oksida, maka secara sinergis konduktifitas air akan meningkat pula dan menyebabkan pembacaan kadar TDS oleh TDS meter menjadi naik pula. Prinsip dasar kerja TDS meter adalah turunan dari nilai konduktifitas suatu larutan. Oleh karenannya kadar TDS produk arsinum setelah dilewatkan resin magnesium oksida mengalami kenaikan.

Rygaard, dkk

menyampaikan bahwa secara ekonomis, komposisi atau kadar maksimum ion magnesium dalam air minum adalah berkisar 10-20 mg per liter. Namun demikian dalam penelitian tersebut tidak disampaikan nilai $\mathrm{pH}$ dari air minum yang digunakan sebagai objek. Bila dibandingkan dengan hasil penelitian ini kadar TDS terendah yang didapatkan masih berada di atas ambang batas yang dianjurkan oleh penelitian sebelumnya. Akan tetapi, tujuan dari penelitian ini dalah mendapatkan kondisi operasi optimal untuk mencapai $\mathrm{pH}$ yang layak untuk diminum.

Penambahan

resin magnesium oksida ke dalam umpan air siap minum untuk meningkatkan $\mathrm{pH}$ nyatanya tidak menyebabkan kadar TDS air siap minum naik melebihi aturan yang berlaku. Pada waktu tinggal terlama pun, kadar TDS masih tetap aman untuk dikonsumsi. Namun demikian kadar TDS terendah yang didapatkan masih dianggap kurang ekonomis menurut penelitian sebelumnya. Oleh karena itu perlu dilakukan penelitian lebih lanjut untuk mengevaluasi perangkat peningkat $\mathrm{pH}$ berbasis resin magnesium oksida ini secara ekonomis. 


\section{KESIMPULAN}

Perangkat peningkat $\mathrm{pH}$ berbasis resin magnesium oksida mampu bekerja secara optimal untuk mencapai prasyarat kelayakan air minum pada kondisi operasi waktu tinggal 16 detik. Pada kondisi tersebut kadar TDS air produk masih berada di bawah batas maksimal yang diperbolehkan. Namun demikian, kelayakan secara ekonomis dari perangkat peningkat $\mathrm{pH}$ berbasis resin magnesium oksida ini masih sangat perlu untuk dikaji dengan lebih mendalam. Bila mempertimbangkan spesifikasi peralatan yang ada dipasaran agaknya peningkat $\mathrm{pH}$ berbasis resin magnesium oksida ini sangat mampu untuk dijadikan alternatif solusi permasalahan rendahnya $\mathrm{pH}$ air produk.

\section{DAFTAR}

\section{PUSTAKA}

Ariyanti, D. and Widiasa, I.N. 2011. Aplikasi Teknologi Reverse Osmosis Untuk Pemurnian Air Skala Rumah Tangga. Teknik, 32(3), pp.193-197.

Badan Pusat Statistik. 2017. Survei Sosial Ekonomi Nasional: Persentase Rumah Tangga menurut Provinsi dan Sumber Air Minum Layak, 1993-2017. https://www.bps.go.id/staticta ble/2009/04/06/1549/persenta se-rumah-tangga-menurutprovinsi-dan-sumber-airminum-layak-1993-2017.html (diakses 20 Juni 2019)

Cotruvo, J. 2006. Health aspects of calcium and magnesium in drinking water. Water conditioning \& purification, 48 , pp.6-40.

Herlambang, A., 2011. Teknologi penyediaan air minum untuk keadaan tanggap darurat. Jurnal Air Indonesia, 6(1).

Kementerian Kesehatan Republik Indonesia. 2012. Peraturan Menteri Kesehatan Republik Indonesia Nomor 492/MENKES/PER/IV/2010 tentang Persyaratan Kualitas Air Minum.

Patnaik, P. 2002. Handbook of inorganic chemicals. McGrawHill.

Qin, J.J., Oo, M.H. dan Coniglio, B. 2005. Relationship between feed $\mathrm{pH}$ and permeate $\mathrm{pH}$ in reverse osmosis with town water as feed. Desalination, 177(1-3), pp.267-272.

Ruggieri, F., Fernandez-Turiel, J.L., Gimeno, D., Valero, F., Garcia, J.C. and Medina, M.E., 2008. Limestone selection criteria for EDR water remineralization. Desalination, 227(1-3), pp.314-326.

Rygaard, M., Arvin, E., Bath, A. and Binning, P.J. 2011. Designing water supplies: optimizing drinking water composition for maximum economic benefit. Water research, 45(12), pp.3712-3722.

Said, N.I. 2009. Uji Kinerja Pengolahan Air Siap Minum dengan Proses Biofiltrasi, Ultrafiltrasi dan Reverse Osmosis (RO) dengan Air Baku Air Sungai. Jurnai Air Indonesia. Jakarta.

Setiadi, I. and Kristyawan, I.P.A., 2018. Teknologi Pengolahan Air Gambut Asin Menjadi Air Siap Minum di Kelurahan Tanjung Tengah, Penajam, Kalimantan Timur. Jurnal Air Indonesia, 8(2). 
Setiadi, I., 2019. Pengaman Laju Air Umpan Untuk Arsinum Kapasitas 5M3/Hari Menggunakan Pressure Switch dan Selenoid Valve. Jurnal Rekayasa Lingkungan, 11(2).

World Health Organization. 2005. Nutrients in drinking water (No. WHO/SDE/WSH/05.09). Geneva: World Health
Organization.

Yudo, S. and Sitomurni, A.I., 2019. Implementasi Teknologi Pengolahan Air Siap Minum dan Pengembangan Usaha Galon Air Siap Minum Studi Kasus: Penerapan Teknologi Pengolahan Air Siap Minum Di SMK Al-Kahfi, Sumbawa. Jurnal Rekayasa Lingkungan, 11(2). 